\title{
LASER-INDUCED BREAKDOWN SPECTROSCOPY AND INDUCTIVELY COUPLED PLASMA-MASS SPECTROMETRY FOR DETERMINATION OF Cr IN SOILS FROM BRITS DISTRICT, SOUTH AFRICA
}

\author{
Abayneh Ataro Ambushe ${ }^{1^{*}}$, Anton du Plessis ${ }^{2}$ and Robert Ian McCrindle ${ }^{3}$ \\ ${ }^{1}$ Department of Chemistry, University of Limpopo, Private Bag x1106, Sovenga 0727, South \\ Africa \\ ${ }^{2}$ Department of Forestry and Wood Science, Stellenbosch University, Stellenbosch 7600, South \\ Africa \\ ${ }^{3}$ Tshwane University of Technology, Department of Chemistry, PO Box 56208, Arcadia 0007, \\ South Africa
}

(Received May 16, 2015; revised August 12, 2015)

\begin{abstract}
Laser-induced breakdown spectroscopy (LIBS) is an emerging analytical technique, which can be used to perform elemental analysis of any material, irrespective of its physical state. In this study, the LIBS technique has been applied for quantification of total $\mathrm{Cr}$ in soil samples collected from polluted areas of Brits, North West Province, South Africa. A Q-switched neodymium-yttrium aluminium garnet (Nd-YAG) laser (10 Hz, $\lambda=1064 \mathrm{~nm}$ ) was employed for generation of a laser-induced plasma on the surface of the soil sample. The atomic emission lines were recorded using an Andor Shamrock SR-303i spectrometer, fitted with an intensified charge-coupled device (ICCD) camera. Detailed investigation of experimental parameters such as gate delay time, gate width and laser pulse energy was conducted. Soil samples were dried, finely ground, sieved and thereafter pelletized before LIBS analysis. Calibration curve for the quantification of $\mathrm{Cr}$ was constructed using certified reference materials of soils and sediments. The concentrations of $\mathrm{Cr}$ in soil samples varied from 111 to 3180 $\mathrm{mg} / \mathrm{kg}$. In order to test the validity of the LIBS results, inductively coupled plasma-mass spectrometry (ICP-MS) was also employed for determination of $\mathrm{Cr}$. The results obtained using LIBS were found to be in good agreement with those of ICP-MS.
\end{abstract}

KEY WORDS: Chromium, Direct determination, Soil, LIBS, ICP-MS

\section{INTRODUCTION}

Pollution of soils by heavy metals such as $\mathrm{Cr}$ is a major public concern. In particular, the contamination of agricultural soils with heavy metals results in accumulation of toxic metals in food crops. The circulation of toxic metals through soils, water and air and their inevitable transfer to the human food chain remains an important environmental issue that entails health risks for humans [1].

Chromium levels in the environment have gained special attention due to the serious health effects of the ionic forms of the metal discharged from industrial sources. In South Africa, environmental pollution by $\mathrm{Cr}$ results mainly from mining and smelting activities [2]. The contamination of soil with $\mathrm{Cr}$ could also be due to industrial processes such as electroplating, tanning, manufacture of pigments and chemicals, mud from oil drilling, textile dying, steel, paint and fertilizer production as well as wood preservation [3-6]. During such industrial activities, $\mathrm{Cr}$ compounds are introduced into the soil and can result in significant adverse biological and ecological effects [7]. Compounds of $\mathrm{Cr}(\mathrm{VI})$ are particularly carcinogenic and mutagenic, and have the capability of crossing cell membranes by way of non-specific anion carriers, causing skin ulcerations, nasal perforations and lung cancer [8, 9]. Thus, the contamination of soil by $\mathrm{Cr}$ has become a great threat for humans and animals.

The need for fast and accurate quantification of $\mathrm{Cr}$ in environmental matrices such as soils has led to the development and continuous improvement of various analytical methods. These

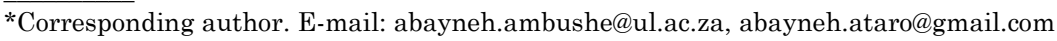


include both sample preparation and the choice of most appropriate instrumental techniques to obtain comprehensive chemical information in the shortest time possible.

Laser-induced breakdown spectroscopy (LIBS) is an alternative analytical tool to other established analytical techniques for elemental analysis. These established methods include flame-atomic absorption spectrometry (F-AAS), inductively coupled plasma-atomic emission spectrometry (ICP-AES) and inductively coupled plasma-mass spectrometry (ICP-MS). However, these techniques require sample pre-treatment and samples are generally introduced as aerosols of aqueous solution. This approach to sample introduction has the desirable features, since a homogeneous analytical sample is easily obtained, external standards are easily prepared, and internal standardization or isotope dilution is straightforward [10]. However, various sample types exist for which dissolution is slow, difficult or inconvenient $[11,12]$. Direct analysis of solid samples offers several benefits compared to traditional sample preparation techniques such as acid digestion and dry ashing. The advantages include short sample preparation time, reduced risk of sample contamination, decreased possibility of analyte loss prior to analysis, increased sensitivity due to less dilution and possibility for selective analysis of micro-amounts of solids [10].

The LIBS technique has been applied for direct analysis of different environmental samples [5, 13-21]. The principles of LIBS have been described elsewhere [13, 22-24]. Briefly, a high power laser beam is focused onto a sample to create a plasma that results from vaporization and atomization of a minute amount of target material. When a transient plasma, which contains neutral and ionized excited states cools, the excited atomic, ionic and molecular fragments within the plasma emit light with specific wavelengths. The emitted light can be recorded, which provides spectra. Each element creates its own spectral fingerprint that corresponds to the emission lines of specific elements present in the sample [25, 26].

The LIBS technique requires little or no sample preparation. In principle, LIBS is able to perform elemental analysis of any kind of sample, irrespective of its physical state [23, 27]. One of the principal advantages of LIBS is that the time required for analysis is very short (seconds); moreover, when required, a fast mapping of the sample surface can be performed in a short time $[28,29]$. The technique has a remarkably broad dynamic range. LIBS simultaneously gives information about elements with concentrations ranging from $100 \%$ down to parts per million $[13,23]$. As only a few micrograms are ablated in the process, LIBS is basically a nondestructive analytical technique [30]. In addition, LIBS has been recognized as a technique which is amenable to field applications [31, 32]. The application of LIBS as a field sensor reduces sampling and sample preparation steps that consume both money and time.

The application of LIBS to soil [6, 24-27, 33-36] and sediment [22, 37, 38] analyses has been of growing interest during the last decade. The LIBS technique has been mainly applied to solve two related problems of soil analysis. Firstly, the assessment of total carbon content, which characterizes the soil enrichment by organic components [35]. Secondly, the determination of levels of nutrients and toxic elements [21, 26, 36, 39].

Pollution of soils around mines by heavy metals such as $\mathrm{Cr}$ has not yet received the attention it deserves in South Africa. The objective of this work was to assess the levels of $\mathrm{Cr}$ in soil samples collected from possibly polluted areas of Brits, North West Province, South Africa, using LIBS. The LIBS technique is an ideal tool for rapid environmental monitoring and mapping of large areas, for example soils around mines, for potential heavy metal pollutants. To the best of our knowledge, this study will be the first of its kind conducted in South Africa that applies LIBS, which is a fast tool to monitor pollution by $\mathrm{Cr}$ in soils around a Ferro-chrome mining area. Although the number of samples is limited in this work, the current study provides an alternative technique for detection of chromium from a complex soil matrix without the need to digest soil samples compared to ICP-MS. This study employed two independent analytical techniques, i.e., LIBS and ICP-MS to quantify $\mathrm{Cr}$ and trace polluted and unpolluted regions of the district. Although ICP-MS provides better precision and sensitivity, LIBS allows having 
immediate analytical response and can be employed for fast monitoring of heavy metals in soils around mines. Finally, with an effort to check accuracy and performance, analytical results obtained with LIBS and ICP-MS were evaluated and compared.

\section{EXPERIMENTAL}

\section{Reagents and standards employed for LIBS and ICP-MS analysis}

The water used in this work was doubly de-ionized with the final stage of de-ionization provided by a Milli-Q water purification system (Simplicity UV, France). High purity $\mathrm{HNO}_{3}$ (65\%, Suprapur, Merck, Darmstadt, Germany) was used for cleaning glassware and digesting soil samples. A stock standard solution containing $1000 \mathrm{mg} / \mathrm{L} \mathrm{Cr}$ obtained from Spectrascan (TEKNOLAB A/S, Kolbotn, Norway), was used for preparing calibration standards for ICP-MS measurements. The calibration solutions were prepared from the stock solution using de-ionized water $(18.2 \mathrm{M} \Omega \mathrm{cm})$ immediately before analysis. The mass calibration stock solution containing $\mathrm{Ba}, \mathrm{Be}, \mathrm{Ce}, \mathrm{Co}, \mathrm{In}, \mathrm{Mg}, \mathrm{Pb}, \mathrm{Rh}$ and $\mathrm{U}$ at $10 \mu \mathrm{g}$ element/L was obtained from PerkinElmer (Concord, Ontario, Canada). Instrument grade argon gas (Afrox, South Africa) was used for the ICP-MS.

For the digestion of soil samples, $40 \% \mathrm{HF}$ and $32 \% \mathrm{HCl}$ obtained from SMM Instruments, South Africa were used. A saturated $\mathrm{H}_{3} \mathrm{BO}_{3}$ solution prepared by dissolving $7.00 \mathrm{~g}$ of $\mathrm{H}_{3} \mathrm{BO}_{3}$ (Merck, Darmstadt, Germany) in $100 \mathrm{~mL}$ of Milli-Q water was used for mineralization of soil samples.

Analytical reagent grade $\mathrm{H}_{3} \mathrm{BO}_{3}$ (Merck, Darmstadt, Germany) was used as a binding agent for preparation of pellets. Pure $\mathrm{K}_{2} \mathrm{CrO}_{4}$ (Merck, Darmstadt, Germany) was used for preparation of a pellet used to identify the best Cr I lines for LIBS measurements. A standard reference material of San Joaquin soil (SRM 2709a, Gaithersburg, MD, USA), certified reference materials of stream sediment (NCS DC 73374, China National Analysis Center for Iron and Steel, Beijing, China) and certified reference materials of soil (NCS DC 73322, China National Analysis Center for Iron and Steel, Beijing, China) were used for construction of calibration curves for LIBS analysis.

\section{LIBS experimental set-up}

The experimental set-up was designed using a Q-switched Nd-YAG laser (Continuum Powerlite 9010, Continuum Inc., Santa Clara, USA). The laser was operated at its fundamental wavelength $(1064 \mathrm{~nm})$ with a pulse of $8 \mathrm{~ns}$ duration and $10 \mathrm{~Hz}$ repetition rate. The laser energy can be adjusted by varying the Q-switched delay time and can deliver a maximum pulse energy of $1 \mathrm{~J}$. The laser energy was measured with a calibrated energy meter (FieldMaxII-TOP, J-50MBYAG, COHERENT, USA) to monitor the dependence of LIBS signal intensity on incident laser pulse energy. The beam from the laser was focused with a lens of $45 \mathrm{~mm}$ focal length and 25.4 $\mathrm{mm}$ diameter onto the soil sample placed on a holder with a translational stage. The experimental set-up was optimised by adjusting the lens-to-sample distance (LTSD), position of collecting lens and fibre, and angle of light collecting fibre, to assure a high SBR. The emission signals were collimated by collecting lenses into an optical fibre placed at an angle of $45^{\circ}$ to the laser beam and coupled to an Andor Shamrock SR-303i spectrometer (Model SR-3031-A, Andor Technology, Ireland). The spectrometer is fitted with a DH734-18F-03 ICCD camera. The spectrometer has three selectable gratings with 300,1200 and $24001 / \mathrm{mm}$, each one being blazed at $300 \mathrm{~nm}$. In this study, the $24001 / \mathrm{mm}$ grating that offered best resolution and $50 \mu \mathrm{m}$ entrance slit were used. Wavelength calibration was conducted with a low pressure $\mathrm{Hg}$-Ar lamp (Model HG-1, Ocean Optics, USA). 
LIBS measurements were conducted by focusing pulses of laser energy of about $100 \mathrm{~mJ}$ onto the sample surface. The emission spectra were collected with a delay time of $0.75 \mu$ s and gate width of $9 \mu$ s after optimization for selected Cr I lines. At least 5 spectra of each sample were collected on different sample spots, each resulting from 20 accumulations. Background subtraction was accomplished by using the nearby wavelength range free from emission lines. LIBS spectra were collected in the 419.237 to $432.514 \mathrm{~nm}$ spectral region. A schematic diagram of the experimental set-up is depicted in Figure 1.

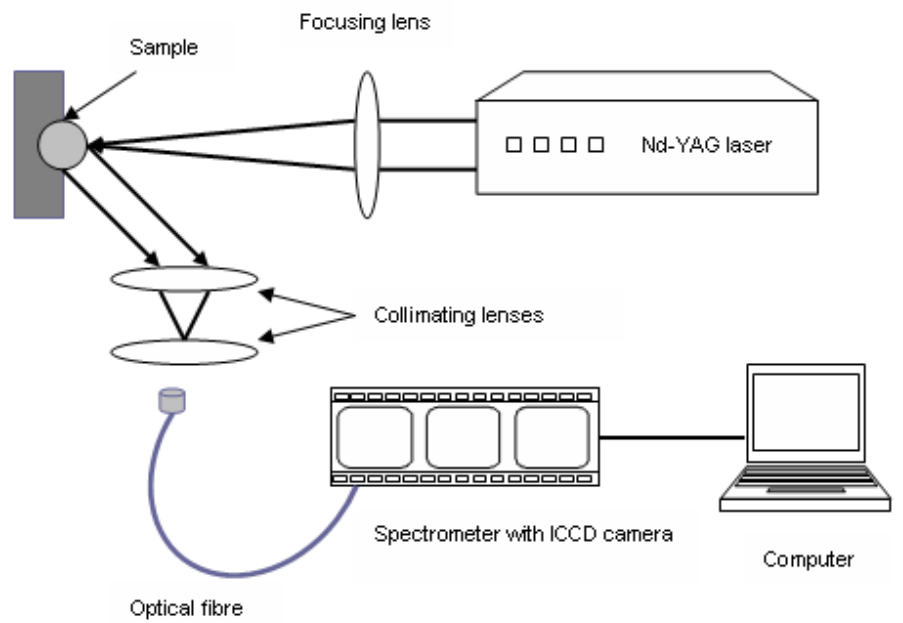

Figure 1. Schematic diagram of experimental set-up used for recording LIBS Spectra of soil sample.

\section{ICP-MS instrumentation}

ICP-MS measurements were performed by a quadrupole ELAN DRC-e spectrometer (PerkinElmer SCIEX, Concord, Ontario, Canada), equipped with a DRC. The sample delivery system consisted of a PerkinElmer Auto Sampler Model AS-93 Plus with as93f.try tray, peristaltic pump and a cross-flow nebuliser with a Scott type double pass spray chamber.

Study area, sampling and sample preparation

Brits is a large town and district situated in North West Province, South Africa. The district plays an important role in the South African mining industry. There is a large Ferro-chrome mine in the district, which is located at $25.39 .38 \mathrm{~S}$ and $27.50 .42 \mathrm{E}$. The mining industry operates two chrome ore mines of about $1.2 \mathrm{Mt}$ per annum and four furnaces with a capacity of about $412 \mathrm{kt}$ per annum. It operates using a closed open furnace in order to reduce particulate emissions [40].

Eight samples of top soil were collected from areas of Brits, North West Province, South Africa. Four soil samples were collected from areas close to a chromium mine and the other four soil samples collected from areas located abut $10 \mathrm{~km}$ away from the site, but within the same geographical area. The sampling sites are shown in Figure 2. Each soil sample was dried in an oven at a temperature of $60{ }^{\circ} \mathrm{C}$ for $24 \mathrm{~h}$. It was then ground with an agate mortar and pestle, and passed through a $75 \mu \mathrm{m}$ sieve. The fraction was preserved in polyethylene bottles prior to analysis. 
For LIBS analysis, dried, finely ground and sieved soil samples of about $4.00 \mathrm{~g}$ were thoroughly mixed with about $0.250 \mathrm{~g}$ of $\mathrm{H}_{3} \mathrm{BO}_{3}$ as a binding agent for preparation of pellets. The pellets were prepared by pressing the mixture using a hydraulic machine (ENERPAC P142, International Crystal Laboratories, USA) to a pressure of 8000 psi. Soil and sediment certified reference materials were used for the construction of calibration curve using LIBS.

Calibration standards were prepared from the $1000 \mathrm{mg} / \mathrm{L}$ stock solution of $\mathrm{Cr}$ for ICP-MS analysis. Millipore water, obtained from Milli-Q water purification system was used throughout this work. The combination of $3.00 \mathrm{~mL} \mathrm{HNO}_{3}, 1.00 \mathrm{~mL} \mathrm{HCl}, 1.00 \mathrm{~mL} \mathrm{HF}$ and $1.00 \mathrm{~mL} \mathrm{H}_{3} \mathrm{BO}_{3}$ $(1.13 \mathrm{~mol} / \mathrm{L})$ were used for mineralization of $0.250 \mathrm{~g}$ of soil samples employing a MARS 5 microwave digestion system (CEM Corporation, USA).

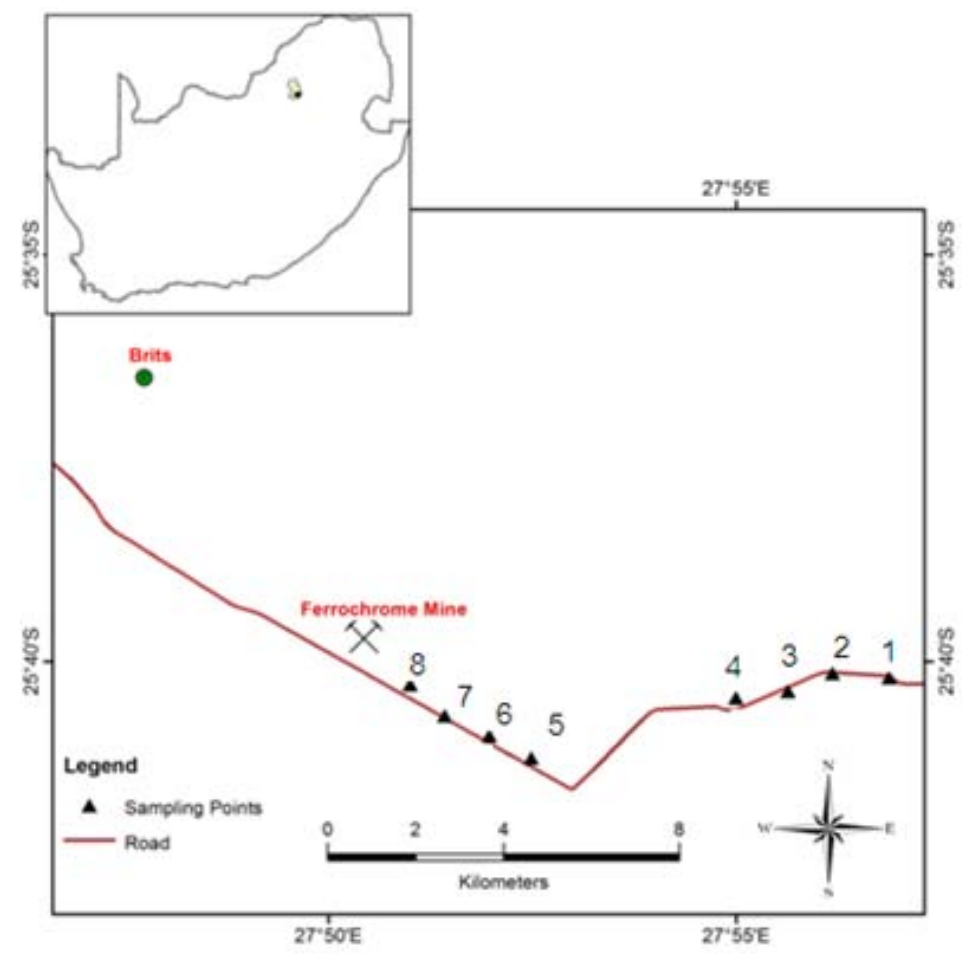

Figure 2. Location map of sampling sites.

\section{RESULTS AND DISCUSSION}

Spectral analysis and quantification of $\mathrm{Cr}$ in soil

The basis of LIBS measurement is the analysis of emission spectra that contains information about the elements of interest in the sample. This information is in the form of emission lines, at specific wavelengths characteristic to the analyte [18]. In this work, all spectra were recorded by accumulating 20 successive laser shots on the target surface. An average of 5 replicate measurements of LIBS intensity, which was collected on different sample spots, was used to calculate concentrations of $\mathrm{Cr}$ in each sample. LIBS spectra recorded in the specific spectral

Bull. Chem. Soc. Ethiop. 2015, 29(3) 
region of 419.237 to $432.514 \mathrm{~nm}$, where the three prominent lines of $\mathrm{Cr}$ exist can be seen in Figure 3. These strong emission lines of $\mathrm{Cr}$ I (425.433, 427.481 and $428.971 \mathrm{~nm}$ ) were identified from soil samples employing the LIBS set-up. Other emission lines due to other elements do exist in this region, however, for this work, the object was to monitor Cr. To identify $\mathrm{Cr}$ I lines in LIBS spectra of soil sample, the LIBS spectra obtained analyzing pure $\mathrm{K}_{2} \mathrm{CrO}_{4}$ was overlayed on the LIBS spectra of soil sample as shown in Figure 3. This clearly shows the presence of $\mathrm{Cr}$ I lines at $425.433,427.481$ and $428.971 \mathrm{~nm}$ in the soil sample. All three lines are the intense lines of $\mathrm{Cr}$ I, which clearly demonstrates the presence of $\mathrm{Cr}$ in appreciable amount in soil collected from the vicinity of mining activities. The NIST atomic spectra database [41], were also used to identify all the spectral lines recorded for $\mathrm{Cr}$ with the LIBS set-up. The spectral region for three $\mathrm{Cr}$ I emission lines selected had minimal interference with weak emission lines from other elements.

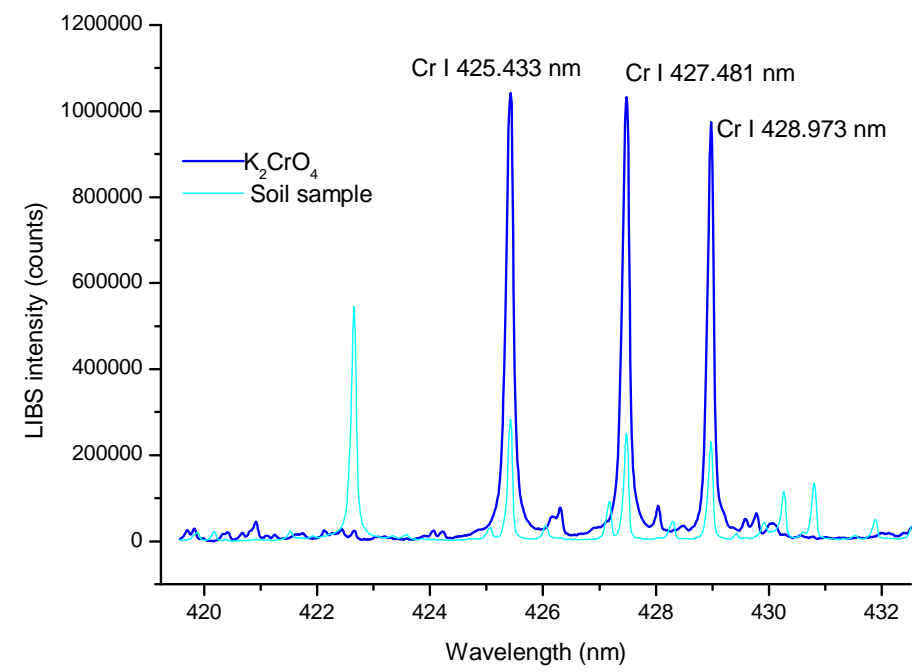

Figure 3. LIBS spectra of $\mathrm{K}_{2} \mathrm{CrO}_{4}$ and soil sample.

A $425.433 \mathrm{~nm}$ Cr I line that yielded the best SBR during gate delay time and laser pulse energy optimisation was selected for subsequent analysis. The calibration curve for $\mathrm{Cr}$ I 425.433 $\mathrm{nm}$ line was constructed using pellets of certified reference material of soils and sediments. The following certified reference materials were used: standard reference material of San Joaquin soil (SRM 2709a), certified reference material of stream sediment (NCS DC 73374) and certified reference materials of soil (NCS DC 73322). The pellets made of SRM 2709a spiked with a known amount of $\mathrm{K}_{2} \mathrm{CrO}_{4}$ with concentrations of 1340 and $3350 \mathrm{mg} / \mathrm{kg}$ of $\mathrm{Cr}$, were prepared to obtain calibration standards 4 and 5, respectively. The mixture was thoroughly mixed and ground to obtain a homogeneous mixture before making the pellets. The calibration curve for Cr I $425.433 \mathrm{~nm}$ line is presented in Figure 4. The LIBS spectra of certified reference materials of soil and sediment used for constructing calibration curve are shown in Figure 5. The calibration curve obtained showed strong linear dependence of the LIBS signal on concentration, as indicated by the linear regression coefficient $(\mathrm{R}=0.99582)$. This strong linear dependence of LIBS intensity on the concentration of $\mathrm{Cr}$ was observed for a wide dynamic range (130 to $3350 \mathrm{mg} / \mathrm{kg}$ ).

Bull. Chem. Soc. Ethiop. 2015, 29(3) 


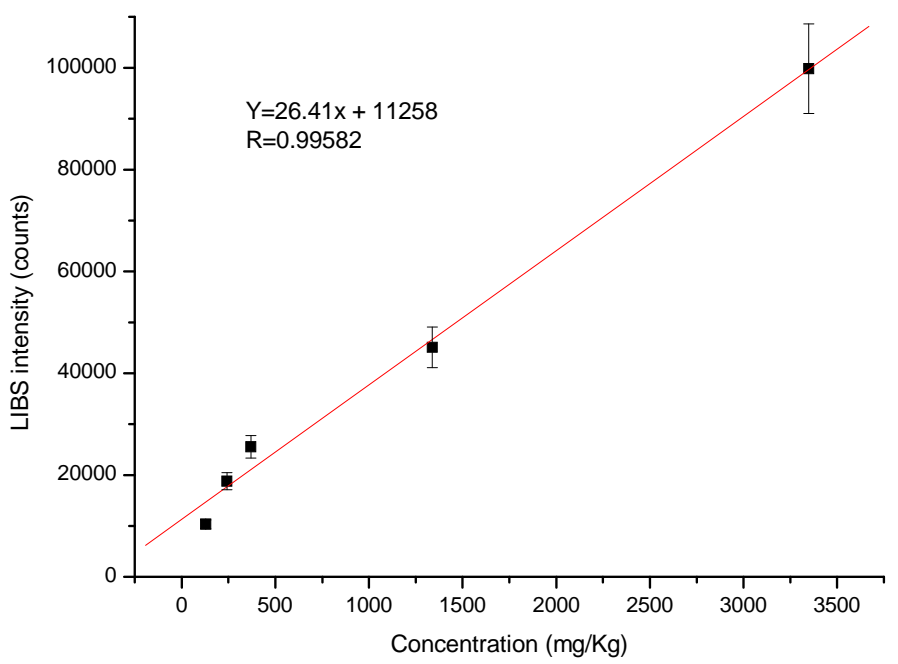

Figure 4. Calibration curve for Cr I $425.433 \mathrm{~nm}$ line.

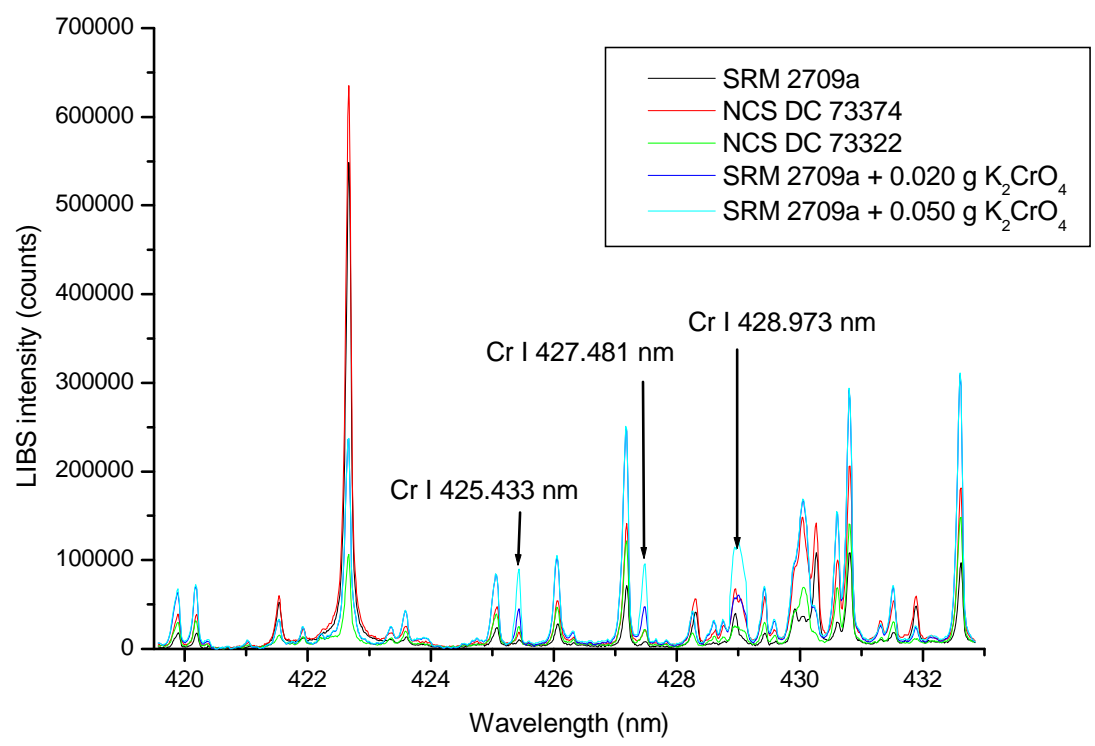

Figure 5. LIBS spectra of certified reference materials of soil and sediment used for constructing calibration curve.

After calibration, total $\mathrm{Cr}$ concentrations in soil samples were quantified by LIBS. The estimated concentrations, together with the standard deviation (SD), are given in Table 1 . The concentrations of total $\mathrm{Cr}$ was determined in eight soil samples using the LIBS set-up and was validated by the analysis of the same soil samples using ICP-MS. The concentrations measured with the LIBS system (Table 1) was in good agreement with the concentrations determined 
using ICP-MS at the $95 \%$ level of confidence as confirmed by t-test. The good agreement between two analytical techniques supports the use of LIBS for the determination of $\mathrm{Cr}$ in soil samples. Thus, LIBS can be considered as an alternative technique for the quantification of $\mathrm{Cr}$ in soil. On the basis of these experimental findings, it is concluded that to quantify $\mathrm{Cr}$ in soil, the Cr I $425.433 \mathrm{~nm}$ line is more suitable than the Cr I 427.481 and $428.973 \mathrm{~nm}$ lines, as evidenced by the best SBR for that line.

Panichev et al. [42] reported total $\mathrm{Cr}$ in soil samples collected from Mpumalanga Province, South Africa, which was the site of a new $\mathrm{Cr}$ mine during the time of investigation. The total $\mathrm{Cr}$ concentrations in their study ranged from 1020 to $1390 \mathrm{mg} / \mathrm{kg}$. This current study showed higher concentrations, ranging from 2130 to $3180 \mathrm{mg} / \mathrm{kg}$ (Table 1) for four samples collected from vicinity of the $\mathrm{Cr}$ mining site. The values are much higher than the maximum permissible level of $150 \mathrm{mg} / \mathrm{kg}$ of $\mathrm{Cr}$ for topsoil that have been set by Soil Association Organic Standards [43]. Such a high concentration of $\mathrm{Cr}$ in soil is dangerous to the ecosystem as it might severely contaminate ground water as well as crops.

Table 1. Comparison of LIBS and ICP-MS results.

\begin{tabular}{|l|c|c|}
\hline \multirow{2}{*}{ Sample ID } & \multicolumn{2}{|c|}{ Concentration of Cr $(\mathrm{mg} / \mathrm{kg}) \pm$ SD } \\
\cline { 2 - 3 } & LIBS & ICP-MS \\
\hline Soil sample 1 & $340 \pm 46$ & $332 \pm 27$ \\
\hline Soil sample 2 & $408 \pm 52$ & $392 \pm 27$ \\
\hline Soil sample 3 & $266 \pm 30$ & $240 \pm 23$ \\
\hline Soil sample 4 & $111 \pm 17$ & $105 \pm 11$ \\
\hline Soil sample 5 & $2920 \pm 291$ & $2530 \pm 208$ \\
\hline Soil sample 6 & $2370 \pm 219$ & $1970 \pm 149$ \\
\hline Soil sample 7 & $2130 \pm 235$ & $3150 \pm 205$ \\
\hline Soil sample 8 & $3180 \pm 271$ & 162 \\
\hline
\end{tabular}

\section{Limit of detection}

The limit of detection (LOD) for the determination of $\mathrm{Cr}$ in soils using LIBS was determined from the calibration curve. The LOD was calculated by $(3 \sigma) / \mathrm{m}$, where $\sigma$ is the standard deviation of the background signal and $m$ is the slope of the calibration curve [27, 44]. The LOD calculation was based on International Union of Pure and Applied Chemistry (IUPAC) method [36]. In this work, the LOD achieved for $\mathrm{Cr}$ in soil was $46.2 \mathrm{mg} / \mathrm{kg}$. The LOD for LIBS is higher due to relatively low sensitivity of the technique compared to ICP-MS and some other trace metals monitoring techniques $[35,45]$.

\section{Accuracy and precision}

The certified reference materials of soils and sediments used for constructing calibration curve were employed to evaluate the accuracy of this method. One of the drawbacks of LIBS is poor accuracy, which was attributed to matrix effects, particle size distribution, sample composition, surface condition and sample inhomogeneity [34, 43]. Despite this limitation, the results obtained using LIBS were in good agreement with those ICP-MS. However, the relative standard deviations (RSD) of LIBS measurements were generally higher than those for ICP-MS measurements. The RSD of $\mathrm{Cr}$ in soil samples for LIBS and ICP-MS measurements were found to be in the range of 8.52 to $15.3 \%$ and 6.50 to $10.5 \%$, respectively (Table 1). The lower precision in LIBS could be attributed to the physical effects related to sample matrix, such as thermal properties, inhomogeneity of analyte content on the pellets surface and texture of the sample [36, 39]. Although ICP-MS provides a better precision, LIBS allows having fast analytical response and can be employed for rapid monitoring of $\mathrm{Cr}$ in polluted areas. 


\section{CONCLUSIONS}

For quantification of $\mathrm{Cr}$ in soil, the $\mathrm{Cr}$ I $425.433 \mathrm{~nm}$ line was found to be more suitable than the Cr I 427.481 and Cr I $428.973 \mathrm{~nm}$ lines. The concentrations of $\mathrm{Cr}$ in soil samples estimated by LIBS agreed with the concentrations found with an ICP-MS. This demonstrates that the LIBS system is a useful alternative tool for the rapid analysis of $\mathrm{Cr}$ in soil samples. A LIBS set-up using an Andor Shamrock SR-303i spectrometer, fitted with an ICCD camera has been established for analysis of soil samples. Thus, we recommend the use of LIBS for rapid quantification of $\mathrm{Cr}$ in Brits district and other $\mathrm{Cr}$ polluted areas.

\section{ACKNOWLEDGEMENTS}

The financial support from African Laser Centre (project no. LHEAB01 Task 11 13) and Rental

Pool Programme (project no. LREEO00) is duly acknowledged.

\section{REFERENCES}

1. Nriagu, J.O.; Pacyna, J.M. Nature 1988, 333, 134.

2. Ambushe, A.A.; McCrindle, R.I.; McCrindle, C.M.E. J. Anal. At. Spectrom. 2009, 24, 502.

3. Kimbrough, D.E.; Cohen, Y.; Winer, A.M.; Creelman, L.; Mabuni, C. Crit. Rev. Environ. Sci. Technol. 1999, 29, 1.

4. Tuzen, M.; Soylak, M. J. Hazard. Mater. 2006, B129, 266.

5. Rai, N.K.; Rai, A.K. J. Hazard. Mater. 2008, 150, 835.

6. Gondal, M.A.; Hussain, T.; Yamani, Z.H.; Baig, M.A. J. Hazard. Mater. 2009, 163, 1265.

7. Kotas, J.; Stasicka, Z. Environ. Pollut. 2000, 107, 263.

8. Underwood, E.J. Trace Elements in Human and Animal Nutrition, 4th ed., Academic Press: New York; 1977; 545.

9. O'Brien, P.; Wang, G. Environ. Geochem. Health 1989, 11, 77.

10. Lee,Y.-L.; Chang, C.-C.; Jiang, S.-J. Spectrochim. Acta Part B 2003, 58, 523.

11. Samek, O.; Beddows, D.C.S.; Telle, H.H.; Morris, G.W.; Liska, M.; Kaiser, J. Appl. Phys. A 1999, 69, S179.

12. Carmona, N.; Oujja, M.; Gaspard, S.; García-Heras, M.; Villegas, M.A.; Castillejo, M. Spectrochim. Acta Part B 2007, 62, 94.

13. Borgia, I.; Burgio, L.M.F.; Corsi, M.; Fantoni, R.; Palleschi, V.; Salvetti, A.; Squarcialupi, M.C.; Tognoni, E. J. Cult. Herit. 2000, 1, S281.

14. Cho, H.-H.; Kim, Y.-J; Jo, Y.-S.; Kitagawa, K.; Arai, N.; Lee, Y.-I. J. Anal. At. Spectrom. 2001, 16, 622 .

15. Gondal, M.A.; Hussain, T.; Yamani, Z.H.; Baig, M.A. Talanta 2006, 69, 1072.

16. Samek, O.; Lambert, J.; Hergenröder, R.; Liška, M.; Kaiser, J.; Novotný, K.; Kukhlevsky, S. Laser Phys. Lett. 2006, 3, 21.

17. Buraklov, V.S.; Tarasenko, N.V.; Nedelko, M.I.; Kononov, V.A.; Vasilev, N.N.; Isakov, S. N. Spectrochim. Acta Part B 2009, 64, 141.

18. Li, J.; Lu, J.; Lin, Z.; Gong, S.; Xie, C.; Chang, L.; Yang, L.; Li, P. Opt. Laser Technol. 2009, 41, 907.

19. Trevizan, L.C.; Santos Jr., D.; Samad, R.E.; Vieira Jr., N.D.; Nunes, L.C.; Rufini, I.A.; Krug, F.J. Spectrochim. Acta Part B 2009, 64, 369.

20. Gondal, M.A.; Seddigi, Z.S.; Nasr, M.M.; Gondal, B. J. Hazard. Mater. 2010, 175, 726.

21. Pandhija, S.; Rai, N.K.; Rai, A.K.; Thakur, S.N. Appl. Phys. B 2010, 98, 231.

22. Lazic, V.; Barbini, R.; Colao, F.; Fantoni, R.; Palucci, A. Spectrochim. Acta Part B 2001, 56,807 . 
23. Miziolek, A.; Palleschi, V.; Schechter, I. Laser-induced breakdown spectroscopy (LIBS)Fundamentals and Applications, Cambridge University Press: Cambridge; 2006; p 620 .

24. Senesi, G.S.; Dell'Aglio, M.; Gaudiuso, R.; De Giacomo, A.; Zaccone, C.; De Pascale, O.; Miano, T.M.; Capitelli, M. Environ. Res. 2009, 109, 413.

25. Capitelli, F.; Colao, F.; Provenzano, M.R.; Fantoni, R.; Brunetti, G.; Senesi, N. Geoderma 2002, 106, 45.

26. Hussain, T.; Gondal, M.A.; Yamani, Z.H.; Baig, M.A. Environ. Monit. Assess. 2007, 124, 131.

27. Pandhija, S.; Rai, A.K. Environ. Monit. Assess. 2009, 148, 437.

28. Kaiser, J.; Galiová, M.; Novotný, K.; Cervenka, R.; Reale, L.; Novotný, J.; Liška, M.; Samek, O.; Kanický, V.; Hrdlicka, A.; Stejskal, K.; Adam, V.; Kizek, R. Spectrochim. Acta Part B 2009, 64, 67.

29. Michel, A.P.M. Spectrochim. Acta Part B 2010, 65, 185.

30. Telle, H.H.; Beddows, D.C.S.; Morris, G.W.; Samek, O. Spectrochim. Acta Part B 2001, 56, 947.

31. Radziemski, L.J. Spectrochim. Acta Part B 2002, 57, 1109.

32. Cuñat, J.; Fortes, F.J.; Cabalín, L.M.; Carrasco, F.; Simón, M.D.; Laserna, J.J. Appl. Spectrosc. 2008, 62, 1250.

33. Hassan, M.; Sighicelli, M.; Ai, A.L.; Colao, F.; Ahmed, A.H.H.; Fantoni, R.; Harith M.A. Spectrochim. Acta Part B 2008, 63, 1225.

34. Hussain, T.; Gondal, M.A. Environ. Monit. Assess. 2008, 136, 391.

35. Belkov, M.V.; Burakov, V.S.; De Giacomo, A.; Kiris, V.V.; Raikov, S.N.; Tarasenko, N.V. Spectrochim. Acta Part B 2009, 64, 899.

36. Kwak, J.-H.; Lenth, C.; Salb, C.; Ko, E.-J.; Kim, K.-W.; Park, K. Spectrochim. Acta Part B 2009, 64, 1105.

37. Barbini, R.; Colao, F.; Fantoni, R.; Lazic, V.; Palucci, A.; Capitelli, F.; van der Steen, H.J.L.. Laser-induced breakdown spectroscopy for semi-quantitative elemental analysis in soils and marine sediments. Proceedings of EARSeL-SIG-Workshop LIDAR, Dresden/FRG, 2000, No. 1, 122.

38. Barbini, R.; Colao, F.; Lazic, V.; Fantoni, R.; Palucci, A.; Angelone, M. Spectrochim. Acta Part B 2002, 57, 1203.

39. Santos Jr., D.; Nunes, L.C.; Trevizan, L.C.; Godoi, Q.; Leme, F.O.; Braga, J.W.B.; Krug, F.J. Spectrochim. Acta Part B 2009, 64, 1073.

40. Olowoyo, J.O.; Odiwe, A.I.; Mkolo, N.M.; Macheka, L. Pol. J. Environ. Stud. 2013, 22, 1135.

41. National Institute of Standards and Technology. NIST electronic database. Available at: http://physics.nist.gov/PhysRefData/ASD/lines_form.html. Accessed 16 November 2011.

42. Panichev, N.; Mandiwana, K.; Foukaridis, G. Anal. Chim. Acta 2003, 491, 81.

43. Soil Association Organic Standards, Heavy Metals in Soil and Manure, Revision 16.4, 2011, $\mathrm{p} 72$.

44. Tran, M.; Sun, Q.; Smith, B.; Winefordner, J.D. Anal. Chim. Acta 2000, 419, 153.

45. Buckley, S.G.; Johnsen, H.A.; Hencken, K.R.; Hahn, D.W. Waste Manage. 2000, 20, 455. 